This is an electronic reprint of the original article. This reprint may differ from the original in pagination and typographic detail.

Author(s): Helttunen, Kaisa; Tero, Tiia-Riikka; Nissinen, Maija

Title: $\quad$ Influence of lower rim C-methyl group on crystal forms and metal complexation of resorcinarene bis-crown-5

Year: $\quad 2015$

Version:

Please cite the original version:

Helttunen, K., Tero, T.-R., \& Nissinen, M. (2015). Influence of lower rim C-methyl group on crystal forms and metal complexation of resorcinarene bis-crown-5. CrystEngComm, 17(19), 3667-3676. https://doi.org/10.1039/C5CE00311C

All material supplied via JYX is protected by copyright and other intellectual property rights, and duplication or sale of all or part of any of the repository collections is not permitted, except that material may be duplicated by you for your research use or educational purposes in electronic or print form. You must obtain permission for any other use. Electronic or print copies may not be offered, whether for sale or otherwise to anyone who is not an authorised user. 
Cite this: DOI: 10.1039/xoxxooooox

Received ooth January 2012 Accepted ooth January 2012

DOI: 10.1039/xoxxo0ooox

www.rsc.org/

\section{Influence of lower rim $C$-methyl group on crystal forms and metal complexation of resorcinarene bis- crown-5}

\author{
Kaisa Helttunen, ${ }^{a}$ Tiia-Riikka Tero ${ }^{\mathrm{a}}$ and Maija Nissinen ${ }^{\mathrm{a}, *}$
}

C-methyl resorcinarene bis-crown-5 (1) with pendant methyl groups at the lower rim was prepared and crystallized in various solvent mixtures with and without selected metal salts. The crystal structures of two polymorphic forms of unsolvated 1 (1-I and 1-II), three solvates (acetonitrile, chloroform and dichloromethane-methanol), and three metal complexes with silver and cesium salts were obtained. The lower rim methyl groups and the block shape of the host promote crystal packing in brick-wall type assemblies, in which the binding cavities are efficiently filled by the crown bridges. Thus, solvents are found in the interstitial space or coordinated to the crown bridges on top of the cavity, whereas more strongly binding metal cations are able to occupy the cavity. The chloroform solvate proved to be a relatively labile crystal form, which transformed to unsolvated form (1-I) over time. Resorcinarene monocrown-5 (2) was obtained as a minor product of the bridging reaction. Two solvate structures (acetonitrile and chloroform-water) of $\mathbf{2}$ are also reported, providing an example of the effect of the missing crown bridge on the solvate structures.

\section{Introduction}

Resorcinarenes, macrocycles with a concave aromatic binding site, are well-known supramolecular hosts for ammonium and alkali metal cations, and small organic molecules. ${ }^{1}$ The resorcinarene cavity consists of four resorcinol rings, which are usually in a bowl-like rcce crown conformation supported by a circle of intramolecular hydrogen bonds between the hydroxyl groups at the upper rim (Fig. 1). Resorcinarene conformation affects its ability to adapt to the shape and size of the guest leading to a great variety in complexation capacity ${ }^{2}$ and, even more so, in the solid state structures of resorcinarenes. ${ }^{3}$ The most remarkable solid state resorcinarene structures include hydrogen bonded dimeric ${ }^{4,5,6}$ and hexameric ${ }^{7,8}$ capsules, as well as tubular assemblies mediated by $\pi \cdots \pi$ interactions ${ }^{9}$. Inclusion of guests, such as ammonium cations or alcohols within the resorcinarene cavity has an important role in the formation of these assemblies.

Hydroxyl group functionalization affects the ability of the resorcinarene to assume different conformations by interfering with the intramolecular hydrogen bonding, ${ }^{10}$ or by restricting the conformation to a permanent crown or boat in resorcinarene cavitands ${ }^{11}$ and in crown ether bridged resorcinarenes, respectively. ${ }^{12,13}$ The lower rim alkyl chain length also has an effect on the resorcinarene conformation, since $r c c c C$-methyl resorcinarene crystallizes in the boat conformation $^{3,6,14,15,16,17,18,19,20}$ more readily than $C$-ethyl or $C$ propyl resorcinarenes, ${ }^{21}$ and other, more rare conformations, such as scoop, ${ }^{22}$ rctt chair ${ }^{19,23}$ and rctt diamond ${ }^{24}$ have been reported in addition to a typical crown conformation ${ }^{25,26}$. The conformational variation has made the $C$-methyl resorcinarene a versatile building block for 2-D and 3-D supramolecular networks, in which resorcinarenes are connected by hydrogen bonding linkers and the lattice cavities are filled with guests, such as ferrocene, ${ }^{26,14}$ ruthenocene, ${ }^{15} \quad m$-xylene ${ }^{16}$ and benzophenone, ${ }^{17}$ or solvents. ${ }^{18}$

Partially $O$-alkylated resorcinarenes have a reduced amount of hydrogen bond donating and functionalization sites at the upper rim, which simplifies the synthetic modification, such as the preparation of crown ether bridged resorcinarenes. ${ }^{12} C_{4^{-}}$ symmetric tetramethoxy resorcinarenes were first synthesized by McIldowie et al., ${ }^{27}$ and the series of different lower rim

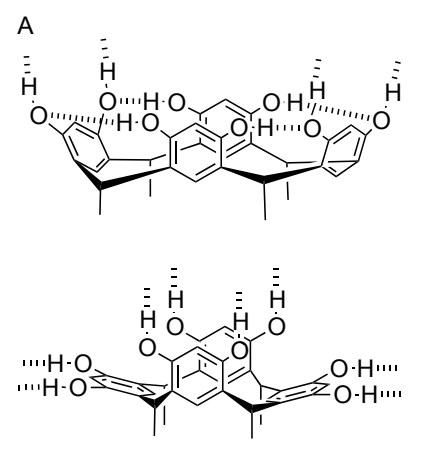

B
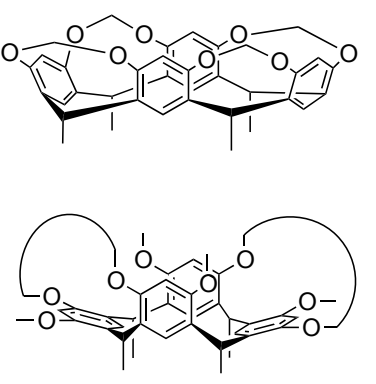

Figure 1. C-methyl resorcinarene in a rccc crown conformation (A, top) and in a rccc boat conformation ( $\mathrm{A}$, bottom) showing typical hydrogen bonding schemes with dashed bonds. The covalently locked crown and boat conformations are shown in (B). 
alkyl chain lengths was recently completed with a $C$-methyl derivative. $^{28}$ The longer alkyl chain tetramethoxy resorcinarenes $\left(\mathrm{C}_{2} \mathrm{H}_{5}-\mathrm{C}_{11} \mathrm{H}_{23}\right)$ have previously been used as starting materials for resorcinarene bis- and mono-crown-5 derivatives, which are synthesized by attaching one or two tetra(ethyleneglycol) bridges to the hydroxyl groups at the upper rim. ${ }^{29,30}$ The crown ether bridged resorcinarene derivatives with a fixed boat conformation have shown a reasonable affinity towards ammonium cations, ${ }^{31}$ alkali metals $\left(\mathrm{K}^{+}, \mathrm{Rb}^{+}, \mathrm{Cs}^{+}\right)^{29,30,32}$ and silver cations. ${ }^{33,34}$ Versatile packing motifs, including layers, ${ }^{30,32,33,34}$ capsules, ${ }^{29,30,33}$ nanorod, ${ }^{33}$ and a helical chain, ${ }^{29}$ especially for the metal complexes of $C$-ethyl resorcinarene bis-crown-5, have been observed. The comparison of the $\mathrm{C}_{2} \mathrm{H}_{5}-\mathrm{C}_{11} \mathrm{H}_{23}$ derivatives of resorcinarene bis-crown-5 has indicated that lower rim alkyl chain affects the self-assembly and crystal packing of the bis-crown-5, but also the complexation properties of the host probably due to solubility differences. ${ }^{30,34}$ These results prompted us to study how the conformational properties of the $C$-methyl resorcinarene manifest in the resorcinarene crown ether derivatives $C$-methyl bis-crown-5 and mono-crown-5, which turned out to show remarkably different solvate formation and crystal packing properties than their longer alkyl chain analogues.

\section{Results and discussion}

Inherently chiral $C$-methyl resorcinarene bis-crown-5 (1, Fig. 2) and mono-crown-5 (2) were synthesized from tetramethoxy resorcinarene $^{28}$ using the protocol previously applied for the long alkyl chain bearing resorcinarenes. ${ }^{29}$ In both cases the resorcinarene framework adopts a permanent boat conformation due to bridging, in which the dihedral angles between the opposing aryl rings describe the openness of the binding cavity. In bis-crown 1, the dihedral angles between the horizontal rings are typically bent over $180^{\circ}$ and the angles between the vertical rings are negative reducing the apparent cavity size in solid state. In mono-crown 2 the crown bridge encloses only one end of the cavity and the other end is open leaving the binding site more exposed.

\section{Unsolvated crystal structures of bis-crown 1}

The unsolvated crystal forms of $\mathbf{1}$ were obtained from 1propanol and by rapid evaporation of chloroform-acetone solution containing traces of DMF (structures 1-I in P $2_{1} / \mathrm{c}$ and 1-II in P-1, respectively). Form 1-I was also obtained from ethyl acetate and several co-crystallization experiments with silver and alkali metal salts, which indicates the stability of this crystal form. Previously, unsolvated crystal forms have only been obtained for $C$-butyl and $C$-pentyl resorcinarene bis-crown derivatives, ${ }^{30}$ whereas $C$-ethyl derivative has crystallized as various solvate structures. ${ }^{29,35}$

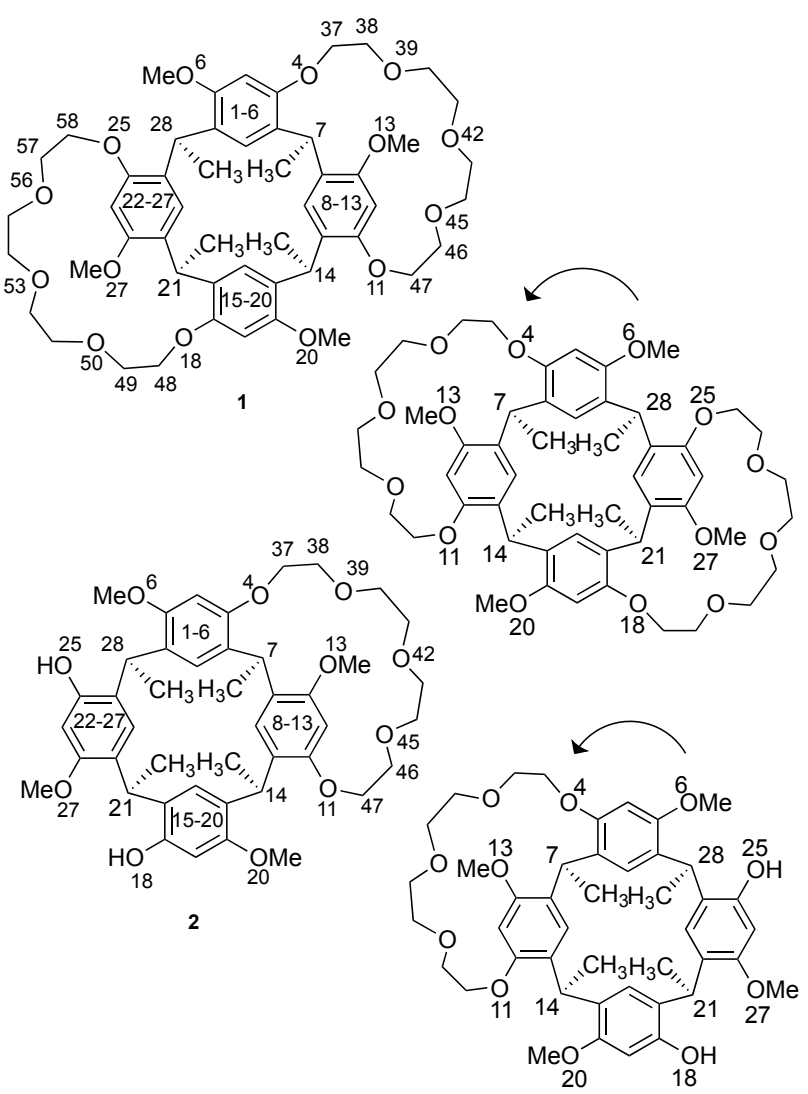

Figure 2. Chemical structure and selected crystallographic numbering of $C$ methyl resorcinarene bis-crown-5 (1) and mono-crown-5 (2) with their left handed enantiomers presented on right.
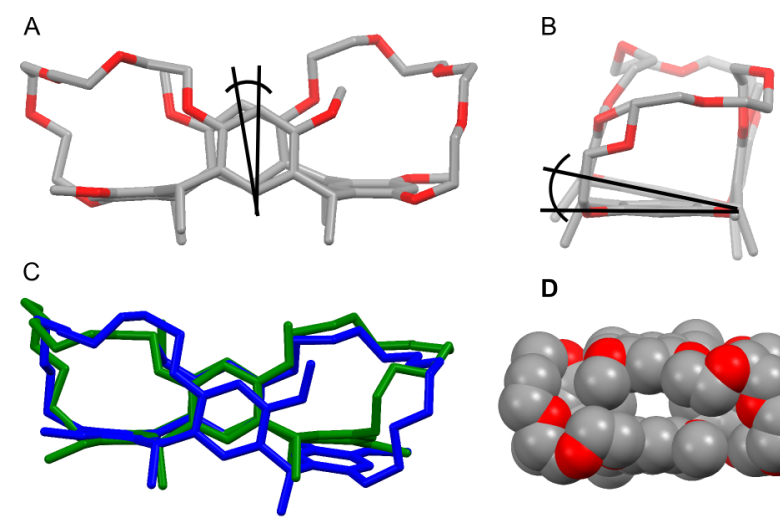

D

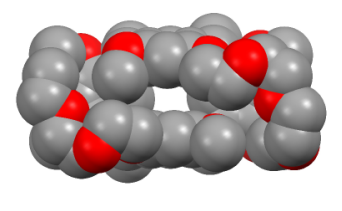

Figure 3. The polymorphic form 1-I: in the front view (A) the tilt angle and in the side view (B) the twist angle is indicated with black lines. A structure overlay (C) of 1-I (blue) and 1-II (green) shows the difference in conformation (overlay calculated for the atom pairs C7, C21 and C28). A top view of 1-I as a CPK model (D). Hydrogen atoms and disorder have been omitted for clarity.

The conformation of $\mathbf{1}$ in polymorph 1-I is a twisted boat with an $8.8^{\circ}$ tilt angle between the vertically aligned aryl rings and a $12.3^{\circ}$ twist angle with respect to the methine bridges (Fig. 3, Table 1). The conformation of polymorph 1-II is less twisted. 

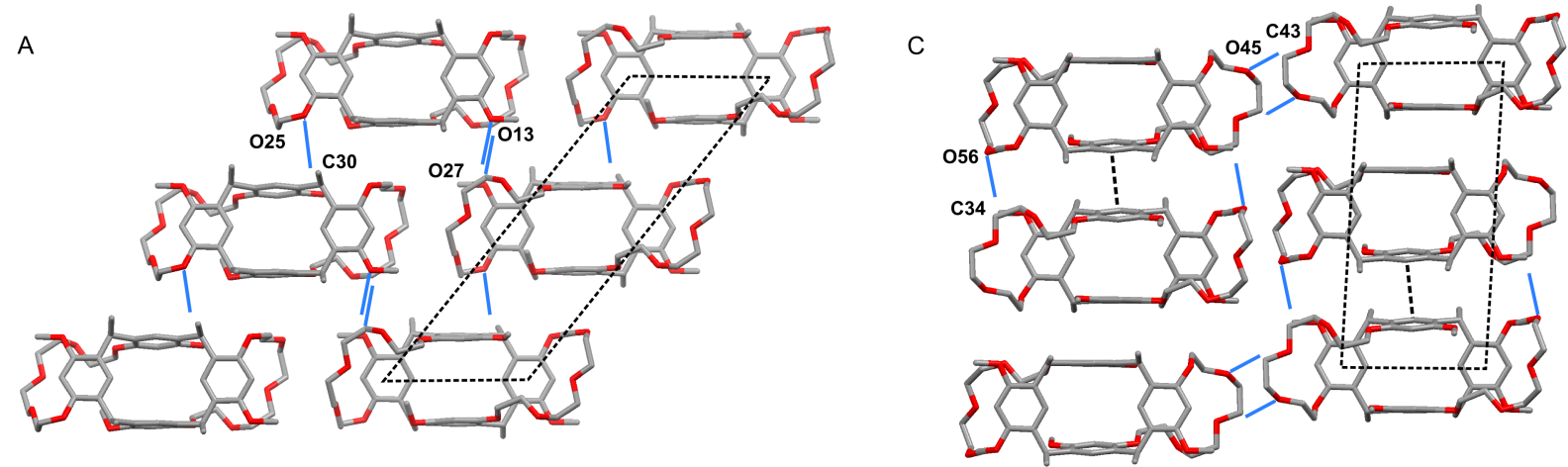

B

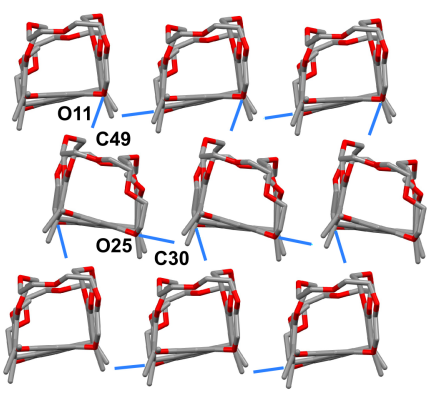

D

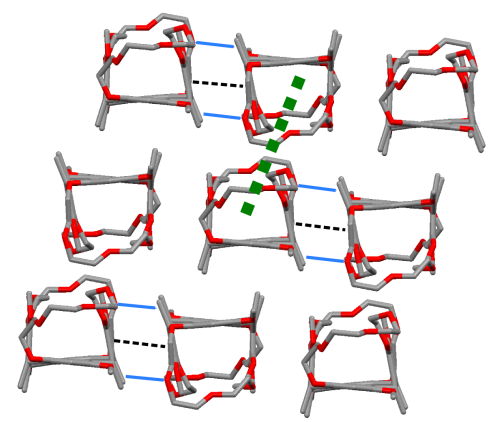

Figure 4. Crystal packing of I- I (A-B) and 1-II (C-D) showing top and side views of packing of the block shaped molecules. Weak hydrogen bonds are shown as blue lines and $\pi \cdots \pi$ stacking with black dashed lines. Dashed parallelogram in the top view indicates the molecules shown in the side view, and thick green dashed line a shifted capsule in 1-II. Hydrogen atoms and disordered atoms omitted for clarity.

\begin{tabular}{|c|c|c|c|c|c|}
\hline Structure & $1-\mathrm{I}$ & 1-II & 1-III & 1-IV & $1-\mathrm{V}$ \\
\hline Crystal & 1 & 1 & 1. & $\mathbf{1} \cdot \mathrm{CH}_{2} \mathrm{Cl} \cdot$ & 1. \\
\hline composition & & & $\mathrm{CH}_{3} \mathrm{CN}$ & $\mathrm{CH}_{3} \mathrm{OH}$ & $\left(\mathrm{CHCl}_{3}\right)_{3}$ \\
\hline Conformation $^{\mathrm{a}}$ & $\begin{array}{l}\text { Twisted } \\
\text { boat }\end{array}$ & Boat & Boat & $\begin{array}{l}\text { Twisted } \\
\text { boat }\end{array}$ & $\begin{array}{c}\text { Twisted } \\
\text { boat }\end{array}$ \\
\hline Tilt $/^{\circ}$ & 8.8 & 5.0 & 0.1 & 5.9 & 12.1 \\
\hline Twist $/{ }^{\circ}$ & 12.3 & 5.4 & 0.1 & 6.8 & 12.0 \\
\hline Distance / $\AA^{\mathrm{b}}$ & $\begin{array}{c}4.86 / \\
8.00\end{array}$ & $\begin{array}{c}4.80 / \\
8.06\end{array}$ & $\begin{array}{c}4.78 / \\
8.00\end{array}$ & $4.68 / 8.00$ & $\begin{array}{c}4.65 / \\
7.89\end{array}$ \\
\hline $\begin{array}{l}\text { Dihedral } \\
\text { angle between } \\
\text { opposite rings } \\
\quad / 0\end{array}$ & $\begin{array}{l}-8.4 / \\
\text { N.D. }\end{array}$ & $\begin{array}{l}-12.0 / \\
\text { N.D. }\end{array}$ & $\begin{array}{c}-10.9 / \\
188.1\end{array}$ & $\begin{array}{l}-15.2 / \\
191.4\end{array}$ & $\begin{array}{l}-14.8 / \\
207.3\end{array}$ \\
\hline $\begin{array}{c}\text { Cavity } \\
\text { diameter / } \AA^{\mathrm{d}}\end{array}$ & $\begin{array}{c}4.77 / \\
5.17\end{array}$ & $\begin{array}{c}5.21 / \\
4.96\end{array}$ & $\begin{array}{c}4.98 / \\
4.98\end{array}$ & $4.61 / 4.96$ & $\begin{array}{c}4.57 / \\
4.60\end{array}$ \\
\hline \multicolumn{6}{|c|}{$\begin{array}{l}{ }^{\mathrm{a}} \text { A twisted boat has twist/tilt angles }>5^{\circ} .{ }^{\mathrm{b}} \text { Centroid-centroid distance } \\
\text { between the opposite aromatic rings. }{ }^{\mathrm{c}} \text { Dihedral angle between the horizontal } \\
\text { aryl rings cannot be determined due to twisting. }{ }^{\mathrm{d}} \text { Average cavity diameter } \\
\text { from the } \mathrm{O} \cdots \mathrm{O} \text { distances. }\end{array}$} \\
\hline
\end{tabular}

The vertically aligned aryl rings in both polymorphs are leaning towards the cavity with dihedral angles of $-8.4^{\circ}$ and $-12.0^{\circ}$, thus reducing the cavity size, which is typical for unsolvated and unoccupied cavities in resorcinarene bis-crowns. As previously observed for the $C$-butyl and $C$-pentyl resorcinarene biscrowns, the empty space inside the binding cavity is filled by the crown ether bridges, which fold on top of the resorcinarene cavity in 1-I and 1-II. In addition, an inward pointing $O$-methyl group C(33) in 1-I fills the rest of the cavity void.

Due to the short methyl groups at the lower rim, the overall shape of the molecule $\mathbf{1}$ is block-like leading to a compact brick-wall type of assembly in 1-I when viewed above (Fig. 4). Weak hydrogen bonds from the lower rim methyl group $\mathrm{C}(30)$ to the upper rim $\mathrm{O}(25)$, and from $\mathrm{C}(40)$ to $\mathrm{O}(27)$ and $\mathrm{C}(51)$ to $\mathrm{O}(13)$ (3.36-3.49 $\AA$ ) connect the rows of $\mathbf{1}$. A side view of the packing reveals a sheet like assembly, in which weak hydrogen bonds $\mathrm{C}(49) \cdots \mathrm{O}(11)$ connect the brick-wall layers. In 1-II the molecules are more clearly aligned to dimers, which are connected by intermolecular $\pi \cdots \pi$ stacking between the aryl rings (C(1)-C(6); Fig. 4) and by weak hydrogen bonds between the methoxy carbon and the crown ether bridge $(\mathrm{C}(34) \cdots \mathrm{O}(56)$, $3.53 \AA)$. The crown ether bridge connecting $\mathrm{O}(4)$ and $\mathrm{O}(11)$ extends more on horizontal direction creating weak hydrogen bonds between $\mathrm{C}(43) \cdots \mathrm{O}(45)$ of the adjacent molecules. The disorder of the crown ether bridge $(\mathrm{C}(41)-\mathrm{O}(42))$ indicates steric freedom in the bridge conformation. A side view of the layers shows resemblance to a shifted capsule packing of the enantiomers, which is a common packing motif for $C$-ethyl biscrown and $C$-ethyl mono-crown solvates. ${ }^{29,31,35}$

\section{Solvate structures of bis-crown 1}

Very stable (stable in solution for several months) 1:1 acetonitrile solvate of compound 1 (1-III in P-1) was obtained by recrystallization from hot acetonitrile. In contrast to the acetonitrile solvate of $C$-ethyl resorcinarene bis-crown which 
encapsulates three acetonitrile molecules inside the cavity, ${ }^{29}$ acetonitrile in 1-III is confined in the interstitial space between the hosts and connected by weak hydrogen bonds from acetonitrile $-\mathrm{CH}_{3}$ to the crown bridge $\mathrm{O}(50)$. As in unsolvated forms the resorcinarene cavity is filled by a folded and disordered crown ether bridge facing a horizontal aromatic ring $(\mathrm{H}(40 \mathrm{~A}) \cdots \mathrm{Ar} 3.12 \AA)$. The conformation of the host is nearly ideal boat conformation, and the molecules pack in a brick-wall type assembly as in 1-I (Fig. 5). The molecules are connected by weak hydrogen bonds between methoxy groups $(\mathrm{C}(36) \cdots \mathrm{O}(13)$ and $\mathrm{C}(34) \cdots \mathrm{O}(27))$ and the "brick" layers further by weak hydrogen bonds $(\mathrm{C}(31) \cdots \mathrm{O}(50))$.

A completely different packing motif was found from a dichloromethane-methanol solvate (1-IV) crystallized in $\mathrm{P} 2{ }_{1} / \mathrm{c}$ with one molecule of dichloromethane, one methanol and resorcinarene $\mathbf{1}$ in the asymmetric unit. Both of the crown ether bridges and dichloromethane molecules are disordered, and dichloromethane and methanol are located on top of the binding cavity via weak hydrogen bonds to the crown ether bridge $(\mathrm{O}(39)$ and $\mathrm{O}(42))$. Molecules of $\mathbf{1}$ are connected in two antiparallel chains by $\mathrm{C}-\mathrm{H} \cdots \mathrm{O}$ bonds $(\mathrm{C}(44) \cdots \mathrm{O}(56)$ and $\mathrm{C}(36) \cdots \mathrm{O}(18), 3.29-3.57 \AA$, Fig. 6A). Furthermore, instead of previous layered assemblies the chains are located at a $68.5^{\circ}$ angle and connected by short contacts between the crown ether

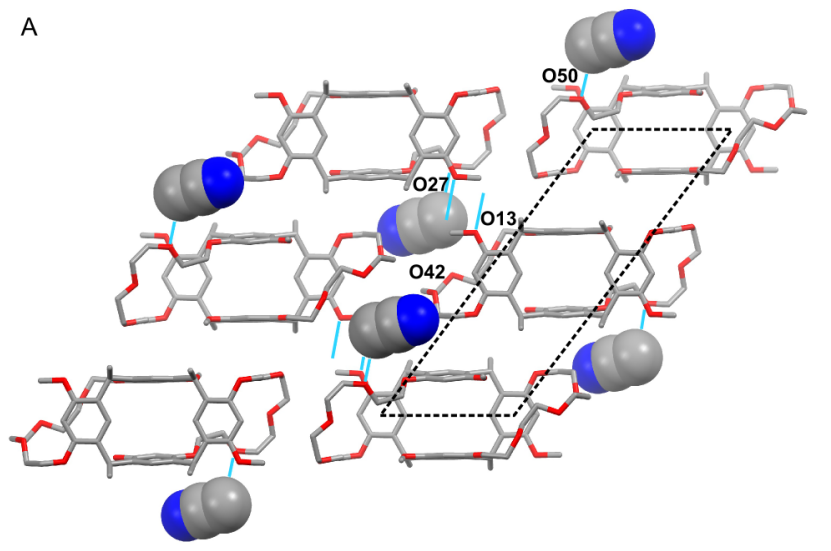

B

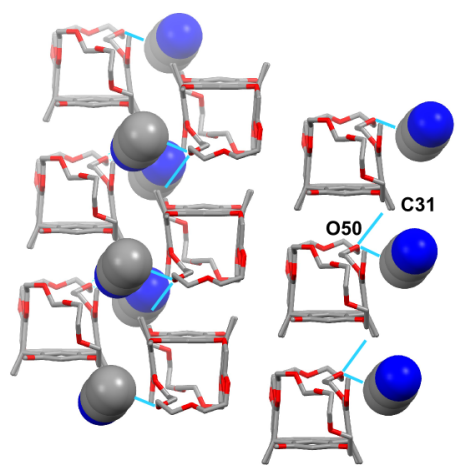

Figure 5. Crystal packing of 1-III showing top (A) and side (B) views of the brickwall packing of the block shaped molecules. Acetonitrile is shown as a space fill model with weak hydrogen bonds to host shown with turquoise lines. A dashed parallelogram in the top view indicates the molecules shown in the side view. Hydrogen atoms and disordered atoms are omitted for clarity.
A
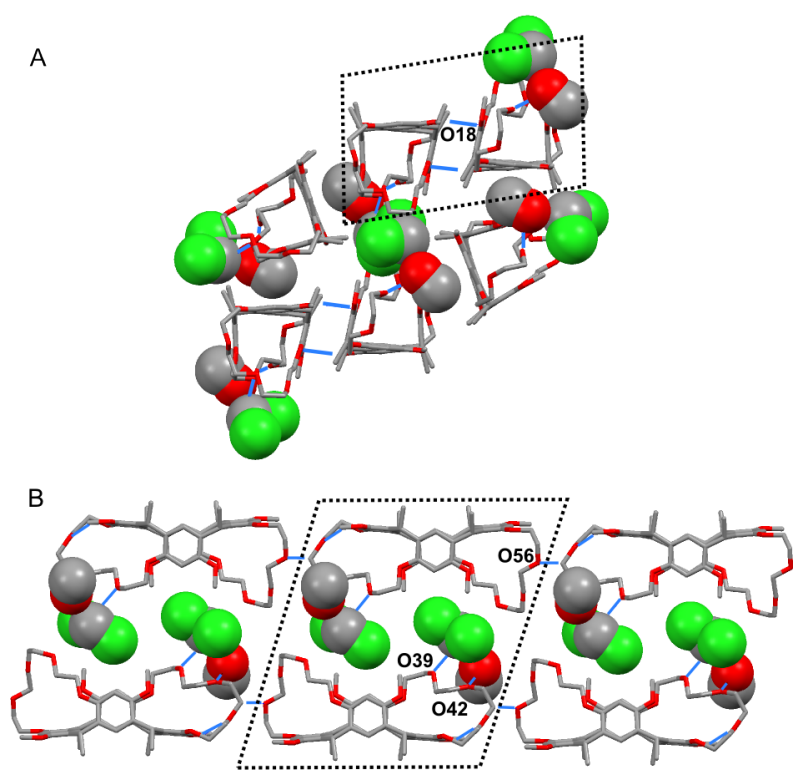

Figure 6. Crystal packing of dichloromethane-methanol solvate 1-IV: a side (A) and a front (B) view. The antiparallel chains in (A) and apparent dimeric assemblies in (B) are marked with dashed parallelograms (hydrogen atoms and disorder are omitted for clarity).

bridge and the lower rim side of the aryl rings. In addition, the upper rim interface of two resorcinarene chains forms an apparent dimer assembly (Fig. 6B), which, however, does not have direct or solvent mediated contacts between the upper and lower resorcinarene molecules.

Slow evaporation crystallization of $\mathbf{1}$ from chloroformmethanol and chloroform-ethanol solutions afforded thin needle crystals within few days. A thicker rod-shaped crystal allowed the structural determination of a chloroform solvate $1-\mathrm{V}$ in $\mathrm{P} 2{ }_{1} / c$ with 3:1 ratio of chloroform and resorcinarene $\mathbf{1}$ in the asymmetric unit (Fig. 7). The conformation of $\mathbf{1}$ is a twisted boat, in which two aryl rings overbend below a horizontal plane giving a curved shape for the molecule. Overbending of the resorcinarene core has been observed in some rare cases for longer alkyl chain derivatives, such as in sodium complex of $C$ ethyl resorcinarene bis-crown $\left(196.7^{\circ}\right),{ }^{29}$ and in $C$-ethyl resorcinarene bis-thiacrowns $\left(195-198^{\circ}\right){ }^{36}$ The cavity of the resorcinarene $\mathbf{1}$ is again fairly closed by the folded crown ether bridges, which bend toward the interior and are held by two intramolecular weak hydrogen bonds to the aromatic rings (C(41) $\cdots \mathrm{O} 11$ and $\mathrm{C}(52) \cdots \mathrm{O} 25), 3.51-3.52 \AA$ ).

The chloroform molecules are well-resolved in the crystal since one of them connects to the vertical aromatic ring of $\mathbf{1}$ by $\mathrm{C}$ $\mathrm{H} \cdots \pi(2.40 \AA)$ interaction and two of them by weak hydrogen bonds to the crown ether bridge oxygens $(\mathrm{O}(39), \mathrm{O}(42)$, and $\mathrm{O}(50), 3.06-3.21 \AA)$. The crystal packing of the host could be described as a puckered layer, in which the crown ether bridges form weak hydrogen bonds $(\mathrm{C}(44) \cdots \mathrm{O} 53$ and $\mathrm{C}(55) \cdots \mathrm{O}(42))$. The layers of $\mathbf{1}$ alternate with the layers of chloroform throughout the crystal lattice. 

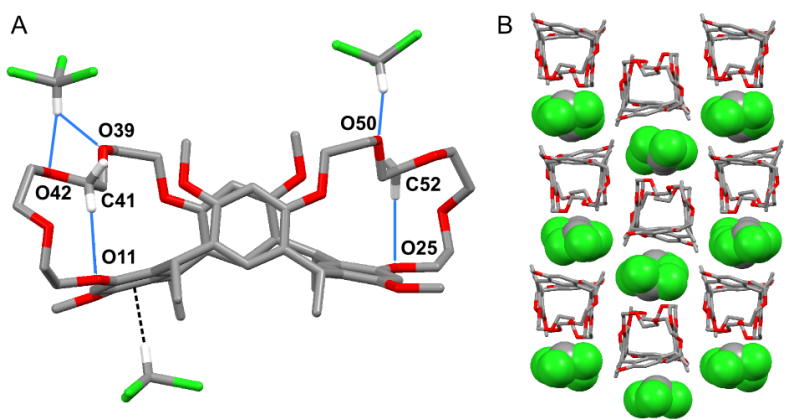

Figure 7. A twisted boat conformation of the labile chloroform solvate 1-V showing weak hydrogen bonds between chloroform and $\mathbf{1}$ with blue lines and C$\mathrm{H} \cdots \pi$ interaction with black dashed line (A). A side view shows puckered layers of 1 and chloroform with a space fill model (B). Hydrogen atoms are not shown for clarity.

After several months of storage in solution $1-\mathrm{V}$ turned into clear block crystals, which were found to be crystals of 1-I. Thus, $\mathbf{1 - V}$ is a kinetically controlled crystal form, whereas very stable crystals 1-I and acetonitrile solvate 1-III are thermodynamically stable phases. The stability difference between the two solvates probably arises from the solubility of 1. Host $\mathbf{1}$ is soluble in chloroform (and DCM) at room temperature and in acetonitrile with heating, but it does not dissolve completely in alcohols even upon heating at approximately $0.5 \mathrm{mg} / \mathrm{ml}$ concentration used for crystallizations. Therefore, ethanol or methanol acts as an antisolvent for chloroform solvated $\mathbf{1}$ enhancing the nucleation of the crystals of kinetically controlled chloroform solvate $\mathbf{1 - V}$.

\section{Solvate structures of mono-crown 2}

$C$-methyl resorcinarene mono-crown (2) has one crown-ether bridge and two free resorcinol hydroxyl groups available for hydrogen bonding. Two solvates, one with $\mathrm{CDCl}_{3} /$ water (2-I) and one with acetonitrile (2-II) were obtained for $\mathbf{2}$, which allow the comparison of the solvate structures and inclusion properties of the resorcinarene cavity with bis-crown 1 .

Compound $\mathbf{2}$ crystallized rapidly from an NMR sample with two molecules of 2, two molecules of water, and one molecule of $\mathrm{CDCl}_{3}$ in the asymmetric unit (2-I, P-1). The host adopts an overbent boat conformation (Table 2) and the crown ether bridge folds inside the cavity forming an exocavity pocket, which binds a chloroform molecule with a bifurcated $\mathrm{C}-\mathrm{H} \cdots \mathrm{O}$ hydrogen bond (Fig. 8). A water molecule is hydrogen bonded to the open end of the resorcinarene cavity and connects two molecules of $\mathbf{2}$ in a horizontal direction. In addition, a hydrogen bond from a resorcinol ring to the crown ether bridge $(\mathrm{O}(18) \cdots \mathrm{O}(39))$ of an opposite facing resorcinarene connects a dimer structure in a vertical direction similarly to previous $C$ ethyl mono-crown structures ${ }^{31}$. The crown ether bridged binding cavity, however, remains empty unlike in the crystal structures of $C$-ethyl resorcinarene mono-crown, where water, methanol and acetonitrile occupy the crown pocket, and the dihedral angles between the horizontal aryl rings are smaller (145-158 $)$.
Table 2. Conformational properties of $\mathbf{2}$.

\begin{tabular}{|c|c|c|c|}
\hline \multirow{2}{*}{$\begin{array}{c}\text { Structure } \\
\text { Crystal } \\
\text { composition }\end{array}$} & \multicolumn{2}{|c|}{$\frac{\text { 2-I }}{\mathbf{2} \cdot\left(\mathrm{CDCl}_{3}\right)_{0.5} \cdot \mathrm{H}_{2} \mathrm{O}}$} & \multirow{2}{*}{$\stackrel{2-\mathrm{II}}{\mathbf{2} \cdot \mathrm{CH}_{3} \mathrm{CN}}$} \\
\hline & A & $\mathrm{B}$ & \\
\hline Conformation & Boat & Boat & Boat \\
\hline Tilt $/{ }^{\circ}$ & 4.1 & 2.2 & 3.6 \\
\hline Twist $/{ }^{\circ}$ & 4.0 & 3.4 & 2.3 \\
\hline Distance / $\AA^{a}$ & $5.10 / 8.00$ & $5.06 / 8.00$ & $4.67 / 8.03$ \\
\hline $\begin{array}{c}\text { Dihedral angle } \\
\text { between } \\
\text { opposite rings / }\end{array}$ & $4.4 / 188.8$ & $2.0 / 186.5$ & $-18.2 / 189.2$ \\
\hline $\begin{array}{c}\text { Cavity diameter } \\
\qquad / \AA^{\mathrm{b}}\end{array}$ & 4.87 & 4.81 & 4.73 \\
\hline
\end{tabular}

${ }^{a}$ Centroid-centroid distance between the opposite aromatic rings. ${ }^{\mathrm{b}}$ Average cavity diameter from the $\mathrm{O} \cdots \mathrm{O}$ distances.
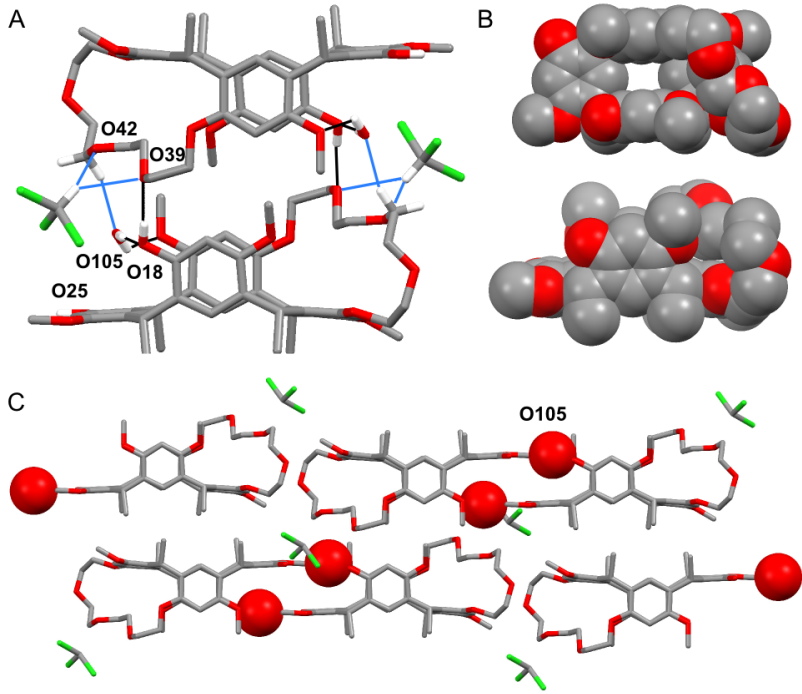

D

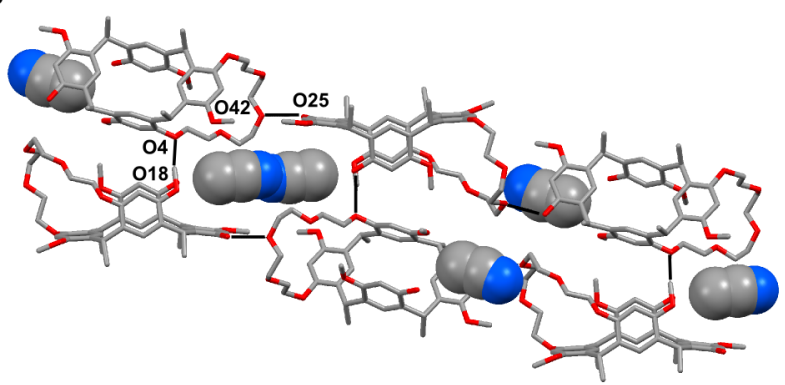

Figure 8. A vertical hydrogen bonded dimer of 2-I (A), a top and a side view as a CPK model (B), and horizontal chains (C); the second molecule of $\mathbf{2}$ in the asymmetric unit is not shown. Hydrogen bonded horizontal chains of 2-II (D). Hydrogen bonds are depicted with black and $\mathrm{C}-\mathrm{H} \cdots \mathrm{O}$ bonds with blue lines, hydrogen atoms and disorder are not shown for clarity.

Recrystallization of $\mathbf{2}$ from acetonitrile provided an acetonitrile solvate 2-II in 1:1 ratio. The crown pocket is in an elongated conformation, which allows two weak intramolecular hydrogen bonds across the cavity $(\mathrm{C}(37) \cdots \mathrm{O}(20)$ and $\mathrm{C}(43) \cdots \mathrm{O}(39))$. An intermolecular hydrogen bond from hydroxyl to the crown ether bridge $(\mathrm{O}(25) \mathrm{H} \cdots \mathrm{O}(42))$ connects left-handed and right-handed enantiomers into horizontal chains (Fig. 8D). In addition, the upper rim hydroxyl group is hydrogen bonded to the 
neighboring molecule $(\mathrm{O}(18) \mathrm{H} \cdots \mathrm{O}(4))$, which is rotated sideways on top of the cavity. The disordered acetonitrile molecule is located at the open end of the binding site forming weak hydrogen bonds to 2 .

The solvate structures of $\mathbf{1}$ and $\mathbf{2}$ indicate that the resorcinarene cavity is not used for inclusion of the solvent molecules, but the crown ether bridge folds inwards filling the cavity and short methyl chains allow compact packing in layers or chains.

\section{Metal complexes of host 1}

Previously, the complexation studies with tetramethoxy resorcinarene bis-crowns have shown that the binding cavity is suitable for the complexation of relatively large alkali metal cations $\left(\mathrm{K}^{+}, \mathrm{Rb}^{+}, \mathrm{Cs}^{+}\right),{ }^{29,30,32}$ and silver $\left(\mathrm{Ag}^{+}\right)^{33,34}$ by cation $\cdots \pi$ and ion-dipole interactions. Based on the previous affinity studies the strongest binding cesium and silver cations were chosen for complexation studies with $\mathbf{1}$ as their $\mathrm{PF}_{6}{ }^{-}$salts. Metal complexation was not attempted with mono-crown $\mathbf{2}$, since mono-crowns are weak hosts for alkali metals. ${ }^{31}$

Complexation of $\mathrm{CsPF}_{6}$ with 1 provided a 1:2 host-to-guest complex with two guest cations and one $\mathrm{PF}_{6}{ }^{-}$anion inside the binding cavity of 1 (1-Cs2, P-1 Fig. 9). A molecule of acetone with occupancy of 0.5 and second $\mathrm{PF}_{6}$ are filling the interstice in the crystal lattice. The cations are coordinated by three $\mathrm{M} \cdots \mathrm{O}$ bonds (3.09-3.23 $\AA$ ) to the crown ether bridge, by two bonds to the $\mathrm{OCH}_{3}$ group (3.21-3.31 $\AA$ ), and, in addition, by cation $\cdots \pi$ interactions to the center of the horizontal aryl rings (cation-centroid distances of 3.33 and $3.44 \AA$ ) similarly to the previously obtained cesium complexes of $C$-ethyl and $C$-propyl bis-crown derivatives. ${ }^{30,32}$ Difference to the structures of the longer alkyl chain resorcinarenes lie in the conformation of $\mathbf{1}$ (Table 3), which is less twisted than $C$-propyl bis-crown but more twisted than $C$-ethyl bis-crown. In addition, 1 has a larger dihedral angle of $161.0^{\circ}$ between the horizontal aromatic rings than $C$-ethyl and $C$-propyl derivatives $\left(152.6^{\circ}\right.$ and $\left.148.8^{\circ}\right)$, which leads to a longer Cs $\cdots$ Cs distance $(6.90 \AA)$ than in previous complexes $(6.42 \AA$ and $6.57 \AA$ for $C$-ethyl and $C$ propyl derivatives, respectively). A wider distance of included cations enables the formation of a capsule-like pairs of righthanded and left-handed enantiomers by $\mathrm{Cs} \cdots \mathrm{F}$ coordination (3.25 $\AA$ ), which was not possible with the shorter Cs $\cdots$ Cs distance. However, the overall packing of the capsules still resembles the layered packing of $C$-propyl resorcinarene biscrown, which formed solvent mediated shifted capsules.

Since twisting of the resorcinarene framework leads to interesting capsule and nanorod structures of $C$-ethyl resorcinarene bis-crown-5 silver complexes, ${ }^{33}$ a considerable effort was placed on the investigation of the $C$-methyl resorcinarene bis-crown-5 silver complexes. Crystallization from pure alcohols provided very small or low quality crystals, likely due to low solubility of the host. Successful crystallization experiments were done in solvent mixtures with $\mathrm{AgPF}_{6}$ and $\mathrm{AgCF}_{3} \mathrm{SO}_{3}$ salts. Crystallization with $\mathrm{AgPF}_{6}$ in acetone yielded a host-guest complex $(1-\mathrm{Ag} 2, \mathrm{C} 2 / \mathrm{c})$, in which two silver cations are located inside the cavity, one $\mathrm{PF}_{6}^{-}$on top
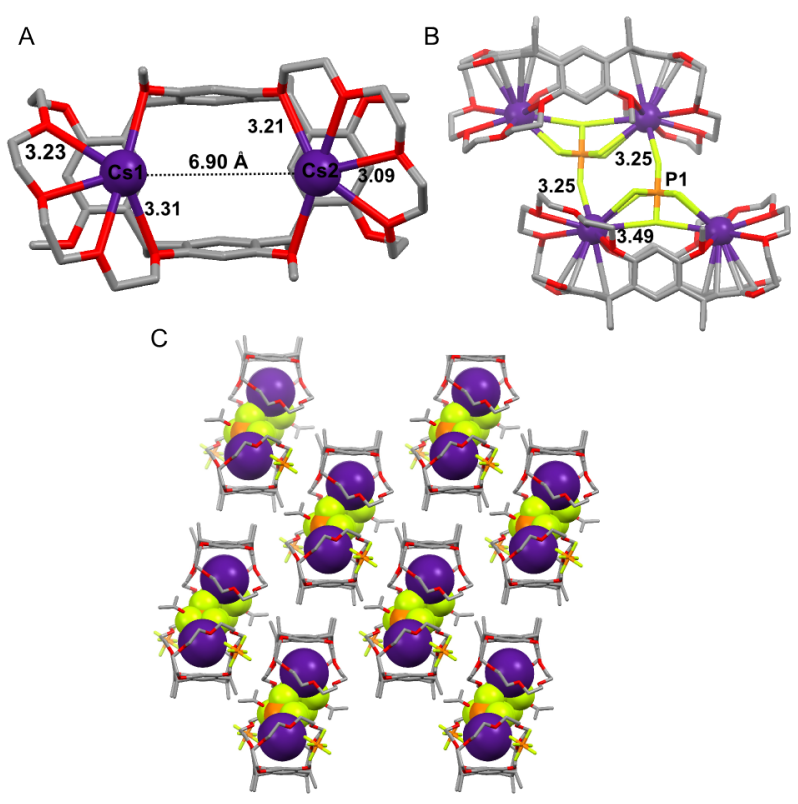

Figure 9. A top view of the Cs coordination in 1-Cs2 complex with the Cs $\cdots \mathrm{O}$ distances in Ångströms ( $\mathrm{A}$; hydrogen atoms and anions removed for clarity), a 1-

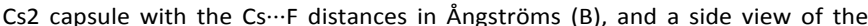
packing of the capsules showing $\mathrm{Cs}$ and the coordinated anions as a CPK-model (C), disorder of the $-\mathrm{CH}_{2} \mathrm{OCH}_{2}$ - unit is not shown.

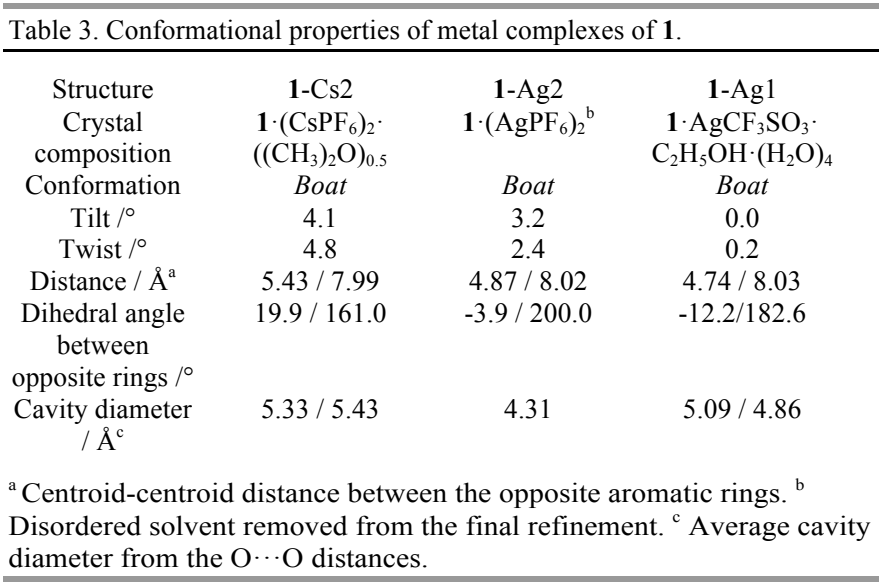

of the cavity, and the other one between two crown bridges and a lower rim of the third resorcinarene (Fig. 10A). The complexation with $\mathrm{AgCF}_{3} \mathrm{SO}_{3}$ in acetone-ethanol-DCM, on the other hand, gave a crystal structure of 1:1 complex (1-Ag1, Pnma), in which an anion and solvent connect a dimeric capsule (Fig. 10B).

In 1:2 complex the silver cations are bound by two $\mathrm{M} \cdots \mathrm{O}$ bonds to the crown ether bridge (2.36-2.51 $\AA$ ) and by one coordination bond to the $\mathrm{OCH}_{3}$ group (2.54 $\AA$ ) similarly to the previous $C$-ethyl and $C$-propyl bis-crown $\mathrm{AgPF}_{6}$ complexes. In addition, silver is connected by $\eta^{2}$ metal-arene coordination $(2.48-2.63 \AA)$ to the proximal edge of the aromatic ring in contrast to previous complexes, in which the coordination was always to the distal edges of the aryl rings. Consequently, the $\mathrm{Ag} \cdots \mathrm{Ag}$ distance is relatively short, $7.10 \AA$, which is likely 
A
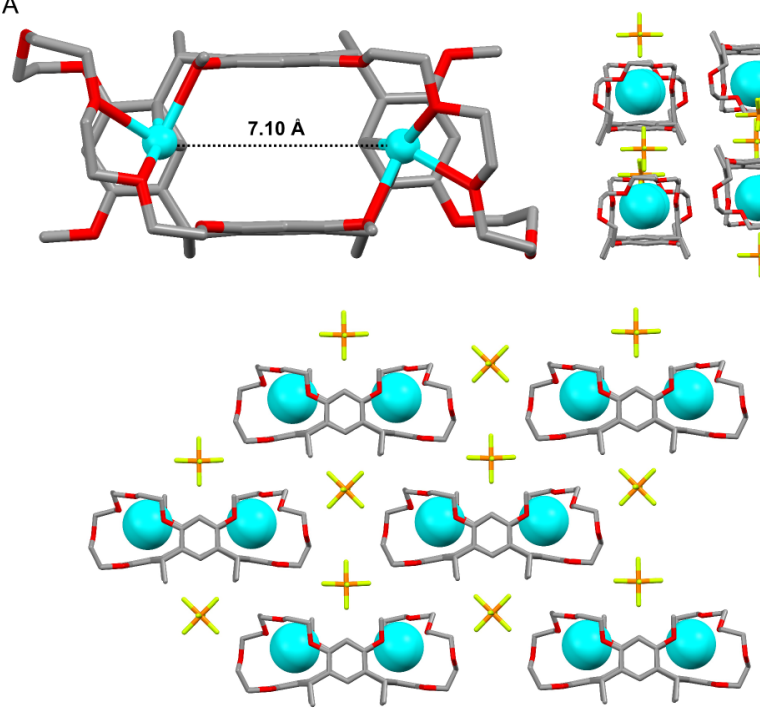

B
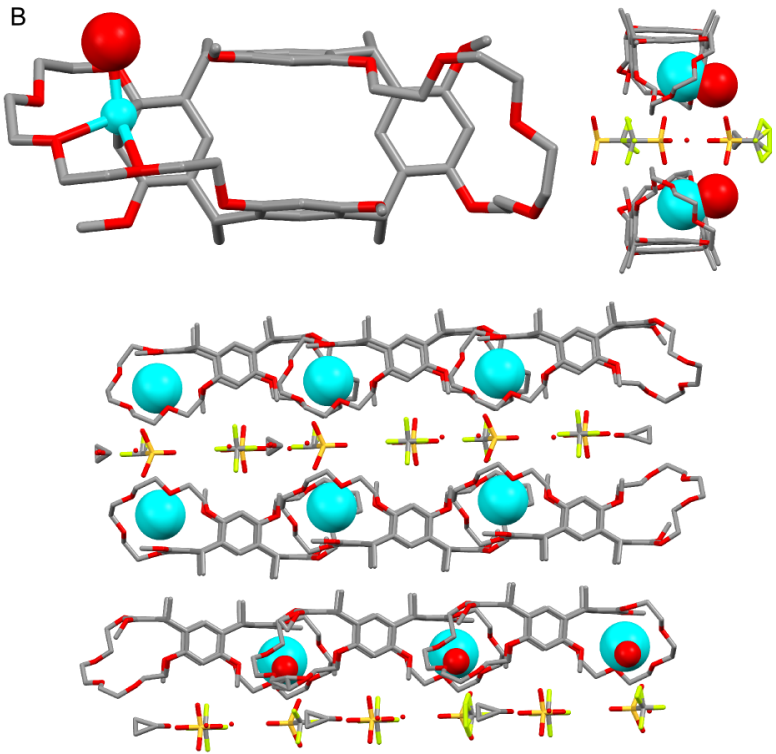

Figure 10. Crystal structures 1-Ag2 (A) and 1-Ag1 (B) compared. A top view of Ag coordination without anions, coordinated water shown as a CPK model in 1-Ag1. Crystal packing from two directions shows enantiomer separated symmetric brick-wall assembly in 1-Ag2 and solvent/anion mediated capsules in 1-Ag1 (triflate anion is disordered over two positions and located on a mirror plane).

due to the interactions with the $\mathrm{PF}_{6}^{-}$anion on top of the cavity. In previous bis-crown silver complexes silver cations were interacting with coordinated solvent molecules (methanol, ethanol, 1- or 2-propanol, or acetone) and the distance between the metals was significantly longer $(\mathrm{Ag} \cdots \mathrm{Ag}=8.8-10.8 \AA) .{ }^{33,34}$ In addition, in $C$-ethyl bis-crown silver complexes the conformation of the host varied from a slightly twisted to significantly twisted boat depending on the size of the solvent coordinated to the included metal. In contrast, the boat conformation of host $\mathbf{1}$ is rather pinched with the horizontal aryl rings overbent in a $200^{\circ}$ dihedral angle and the vertical aryl rings leaning slightly towards each other making the shape of $\mathbf{1}$ a compact block. The crystal packing of 1-Ag2 is composed of symmetric brick-wall type of sheets when viewed from front, in which each layer constitutes of a single enantiomer.

In 1:1 complex silver is coordinated by two $\mathrm{Ag} \cdots \mathrm{O}$ bonds (2.43-2.44 $\AA$ ) to the crown ether bridge and by $\eta^{2}$ metal $\cdots$ arene coordination $(2.50-2.61 \AA)$ to the distal edge of the aromatic ring resembling the earlier examples of silver complexes (Figure 10). ${ }^{33,34}$ In addition, a water molecule forms a coordination bond $(2.31 \AA)$ to the cation on an open side of the binding pocket. The empty side of the cavity is filled by the inward leaning vertical aryl rings (dihedral angle $-12.2^{\circ}$ ) and a folded crown ether bridge in contrast to $1: 1$ silver complex of $C$-ethyl bis-crown capsule, in which the second binding pocket was filled with methanol and water molecules. Two enantiomeric 1:1 complexes form ethanol, water and triflate anion mediated capsules, in which the silver cations are located on top of each other.

\section{Conclusions}

$C$-methyl resorcinarene bis-crown-5 (1) and mono-crown-5 (2) with the shortest possible alkyl chains at the lower rim were synthesized. The short methyl chain induces interesting structural and packing properties in solid state, namely, the ability to adapt to different conformations and an overbent boat conformation. The conformation of the resorcinarene biscrowns and mono-crowns is always locked to a boat conformation but, nevertheless, there are possibilities to conformational variation, such as twisting and tilting, which play interesting role in the crystal packing of resorcinarene biscrowns.

$C$-methyl bis-crown-5 (1) crystallized readily in two solventfree brick-wall assemblies, 1-I and 1-II, due to the block-like shape of the molecule, in which the crown ether bridges are folded inside the cavity. Three different solvate structures for $\mathbf{1}$ were obtained, in which the solvent molecules occupy the interstitial space between hosts in the crystal lattice. The chloroform solvate $(1-\mathrm{V})$ formed a crystal with alternating solvent and host layers, but transformed to the crystal form 1-I over time in solution indicating the thermodynamic stability of the polymorph 1-I. The mono-crown-5 solvates 2 -I and 2-II also had solvents only outside the binding pocket in contrast to $C$-ethyl mono-crown solvates, in which the cavity was used for solvent inclusion. The results indicate that the short methyl groups at the lower rim induce a conformation that does not favor solvent inclusion. In addition, the twisting observed in 1-I occurs readily and leads to the efficient packing of the molecules in solvent-free crystals.

Host 1 was co-crystallized with cesium and silver salts producing three different metal complex structures. In the cesium complex 1-Cs2, long Cs $\cdots \mathrm{Cs}$ distance and large dihedral angle between horizontal aryl rings enabled crystal packing into a dimeric capsule. In the silver complex 1-Ag2, overbending of the boat conformation along with short $\mathrm{Ag} \cdots \mathrm{Ag}$ distance was observed. In 1:1 host-silver complex 1-Ag1, the unoccupied binding pocket was efficiently filled with a folded 
crown bridge. Thus, the unique conformational tendencies of $C$ methyl resorcinarene affect the complexation properties of resorcinarene bis-crown-5 in the solid state when compared to hosts with same binding site and longer pendant alkyl chains.

\section{Experimental}

\section{Crystallography}

Single crystal X-ray data were recorded on a Nonius Kappa CCD diffractometer with Apex II detector using graphite monochromatized $\mathrm{CuK}_{\alpha}(\lambda=1.54178 \AA)$ radiation for structures 1-II and 1-III. The data were processed and absorption correction was made with Denzo-SMN v.0.97.638. ${ }^{37}$ Single crystal X-ray data for structures 1-I, 1-IV 1-Ag1, 1-Ag2, 1-Cs2 and 2-II was collected on an Agilent Supernova Dualsource diffractometer using an Agilent Atlas CCD detector with monochromated $\mathrm{CuK}_{\alpha}(\lambda=1.54180 \AA)$, and for structures 1-V and 2-I on a Agilent Supernova diffractometer using an Agilent Eos CCD detector with monochromated $\operatorname{MoK}_{\alpha}(\lambda=$ $0.71070 \AA$ ). The data were processed and empirical absorption correction was made with CrysAlisPro. ${ }^{38}$ The structures were solved using SHELX-97 software package ${ }^{39}$ or Olex $2^{40}$ (olex2.solve with charge flipping or SHELXS with direct methods). The structure refinement was made with Olex2 using $\mathrm{XL}$ refinement package with least squares minimization. The hydrogen atoms were calculated to their idealized positions with isotropic temperature factors (1.2 or 1.5 times the $\mathrm{C}$ temperature factor) and refined as riding atoms unless otherwise mentioned. CCDC 1042079-88 contains the supplementary crystallographic data for this paper. These data can be obtained free of charge from The Cambridge Crystallographic Data Centre via www.ccdc.cam.ac.uk/data_request/cif.

1-I: Single crystals of $\mathrm{C}_{52} \mathrm{H}_{68} \mathrm{O}_{14}(M=917.06 \mathrm{~g} / \mathrm{mol})$ were crystallized from 1-propanol. Crystal form 1-I was also obtained from crystallization in acetonitrile with $\mathrm{AgPF}_{6}$, in acetone-2-propanol (1:1) with $\mathrm{AgPF}_{6}$, in acetone-ethanol 1:1 with $\mathrm{AgBF}_{4}$, in ethylacetate, in $\mathrm{CDCl}_{3}$-acetone- $\mathrm{d}_{6}(1: 12)$ with $\mathrm{AgPF}_{6}$ and in $\mathrm{CDCl}_{3}$-acetone- $\mathrm{d}_{6}(1: 12)$ with $\mathrm{KPF}_{6}$. Colourless needle crystal $0.3 \times 0.1 \times 0.05 \mathrm{~mm}$, monoclinic, $\mathrm{P} 21 / \mathrm{c}$ (no. 14), $a=11.0209(1) \AA, b=16.0930(2) \AA, c=26.6261(4) \AA, \beta=$ 90.074(1) $)^{\circ} V=4722.38(10) \AA^{3}, Z=4, T=123.00(10) \mathrm{K}, \mu(\mathrm{Cu}$ $\left.\mathrm{K}_{\alpha}\right)=0.760, D_{\text {calc }}=1.290 \mathrm{mg} / \mathrm{mm}^{3}, 28596$ reflections measured $(6.42 \leq 2 \theta \leq 148.94), 9459$ unique $\left(R_{\text {int }}=0.0314\right), R_{1}=0.0499$ $(>2 \sigma(\mathrm{I})), w R_{2}=0.1455$ (all data), $\mathrm{GoF}=1.023$.

1-II: Single crystals of $\mathrm{C}_{52} \mathrm{H}_{68} \mathrm{O}_{14}(M=917.06 \mathrm{~g} / \mathrm{mol})$ crystallized rapidly from $\mathrm{CHCl}_{3}$-acetone (8:2) solution with a trace of DMF after evaporation of the solvent. Colourless rod crystal $0.1 \times 0.02 \times 0.02 \mathrm{~mm}$, triclinic, P-1 (no. 2), $a=$ 11.3557(13) $\AA, b=13.324(2) \AA, c=16.537(3) \AA, \alpha$ $=108.171(8)^{\circ}, \beta=94.406(8)^{\circ}, \gamma=92.266(7)^{\circ}, V=2365.0(6)$ $\AA^{3}, Z=2, T=173 \mathrm{~K}, \mu\left(\mathrm{Cu} \mathrm{K}_{\alpha}\right)=0.759, D_{\text {calc }}=1.288 \mathrm{mg} / \mathrm{mm}^{3}$, 11456 reflections measured $(5.64 \leq 2 \theta \leq 133.8), 8121$ unique $\left(R_{\text {int }}=0.0815\right), R_{1}=0.0556(>2 \sigma(\mathrm{I})), w R_{2}=0.1503$ (all data), $\mathrm{GoF}=1.027$. C41-O42 $\left(-\mathrm{CH}_{2} \mathrm{O}-\right)$ are disordered over two positions (0.87:0.13) and restrained with SADI, DELU and SIMU.

1-III: Single crystals of $\mathrm{C}_{52} \mathrm{H}_{68} \mathrm{O}_{14} \cdot \mathrm{C}_{2} \mathrm{H}_{3} \mathrm{~N}(M=958.12 \mathrm{~g} / \mathrm{mol})$ were crystallized from acetonitrile solution. Colourless block crystal $0.1 \times 0.1 \times 0.1 \mathrm{~mm}$, triclinic, P-1 (no. 2), $a=8.9268$ (3) $\AA, b=14.4126(7) \AA, c=20.6525(11) \AA, \alpha=85.264(2)^{\circ}, \beta=$ $85.152(2)^{\circ}, \gamma=73.771(3)^{\circ}, V=2537.3(2) \AA^{3}, Z=2, T=173 \mathrm{~K}$, $\mu\left(\mathrm{Cu} \mathrm{K} \mathrm{K}_{\alpha}\right)=0.735, D_{\text {calc }}=1.254 \mathrm{mg} / \mathrm{mm}^{3}, 12142$ reflections measured $(6.40 \leq 2 \theta \leq 133.86), 8756$ unique $\left(R_{\text {int }}=0.0486\right), R_{1}$ $=0.0526(>2 \sigma(\mathrm{I})), w R_{2}=0.1393$ (all data), $\mathrm{GoF}=1.018$. C41$\mathrm{O} 42-\mathrm{C} 43\left(-\mathrm{CH}_{2} \mathrm{OCH}_{2}\right)$ are disordered over two positions (0.84:0.16), restrained with SADI, DELU, and SIMU, and constrained with EADP (C41/C41B).

1-IV: Single crystals of $\mathrm{C}_{52} \mathrm{H}_{68} \mathrm{O}_{14} \cdot \mathrm{CH}_{2} \mathrm{Cl}_{2} \cdot \mathrm{CH}_{4} \mathrm{O}(M=1034.03$ $\mathrm{g} / \mathrm{mol}$ ) were crystallized from dichloromethane layered with $\mathrm{NaClO}_{4}$ in methanol. Colourless plate crystal $0.3 \times 0.2 \times 0.1$ $\mathrm{mm}$, monoclinic, $\mathrm{P} 2{ }_{1} / \mathrm{c}$ (no. 14), $a=17.9718(4) \AA, b$ $=19.3215(3) \AA, c=15.5981(2) \AA, \beta=102.1831(17)^{\circ}, \mathrm{V}=$ 5294.30(16) $\AA^{3}, \mathrm{Z}=4, T=123.01(10) \mathrm{K}, \mu(\mathrm{Cu} \mathrm{K} \alpha)=1.658$, $D_{\text {calc }}=1.297 \mathrm{~g} / \mathrm{mm}^{3}, 17795$ reflections measured $(6.8 \leq 2 \theta \leq$ 148.5), 10237 unique $\left(R_{\text {int }}=0.0321\right), R_{1}=0.0932(\mathrm{I}>2 \sigma(\mathrm{I}))$ $w R_{2}=0.2996$ (all data), GoF $=1.075 . \mathrm{O} 42-\mathrm{C} 43\left(-\mathrm{OCH}_{2}\right)$ are disordered over two positions $(0.88: 0.12)$, restrained with SADI, DELU, and SIMU, and constrained with EADP (O42/O42A). C48-C49-O50-C51-C52 are disordered over two positions (0.69:0.31) and restrained with SADI, DELU, and SIMU. $\mathrm{CH}_{2} \mathrm{Cl}_{2}$ is disordered over two positions (0.78:0.22), restrained with DFIX 1.79 and constrained with EADP for $\mathrm{Cl} 2$. 1-V: Single crystals of $\mathrm{C}_{52} \mathrm{H}_{68} \mathrm{O}_{14} \cdot\left(\mathrm{CHCl}_{3}\right)_{3} \quad(M=1275.17$ $\mathrm{g} / \mathrm{mol}$ ) were crystallized from ethanol-chloroform (3:2) solution as needles and rods. The crystals transformed into polymorphic form 1-I after several months in solution. Colourless rod crystal $0.4 \times 0.1 \times 0.1 \mathrm{~mm}$, monoclinic, $\mathrm{P} 2_{1} / \mathrm{c}$ (no. 14), $a=17.5687(4)$ $\AA, b=23.0884(5) \AA, c=15.7904(3) \AA, \beta=108.034(2)^{\circ}, V=$ $6090.5(2) \AA^{3}, T=173 \mathrm{~K}, Z=4, \mu\left(\mathrm{Mo} \mathrm{K}_{\alpha}\right)=0.475, D_{\text {calc }}=$ $1.391 \mathrm{mg} / \mathrm{mm}^{3}, 21409$ reflections measured $(5.96 \leq 2 \theta \leq$ $53.38), 11877$ unique $\left(R_{\text {int }}=0.0251\right), R_{1}=0.0860(>2 \sigma(\mathrm{I}))$, $w R_{2}=0.2632$ (all data), GoF $=1.022$. Largest difference peak $1.28 \mathrm{e} \cdot \AA^{-3}$ located $1.16 \AA$ from $\mathrm{C} 101$ indicates residual electron density around $\mathrm{CHCl}_{3}$. Disorder model for solvates did not improve the structure model and was therefore not used in the final refinement.

1-Cs2: Single crystals of $\left[\mathrm{Cs}_{2}\left(\mathrm{PF}_{6}\right)\left(\mathrm{C}_{52} \mathrm{H}_{68} \mathrm{O}_{14}\right)\right]\left(\mathrm{PF}_{6}\right)\left(\mathrm{C}_{3} \mathrm{H}_{6} \mathrm{O}\right)_{0.5}$ $(M=1501.86 \mathrm{~g} / \mathrm{mol})$ were crystallized from acetone-DCM (10:1) with excess of $\mathrm{CsPF}_{6}$. Colourless block crystal $0.16 \times$ $0.05 \times 0.05 \mathrm{~mm}$, triclinic, P-1 (no. 2), $a=13.2706(3) \AA, b=$ $15.2318(3) \AA, c=16.1051(4) \AA, \alpha=80.059(2)^{\circ}, \beta=$ $89.360(2)^{\circ}, \gamma=88.922(2)^{\circ}, V=3205.86(13) \AA^{3}, Z=2, T=$ $123.01(10) \mathrm{K}, \mu\left(\mathrm{Cu} \mathrm{K}_{\alpha}\right)=10.169 \mathrm{~mm}^{-1}, D_{\text {calc }}=1.556 \mathrm{~g} / \mathrm{mm}^{3}$, 21759 reflections measured $(8.72 \leq 2 \theta \leq 151.98), 12904$ unique $\left(R_{\text {int }}=0.0303\right), R_{1}=0.0408(>2 \sigma(\mathrm{I})), w R_{2}=0.1138$ (all data), $\mathrm{GoF}=1.029$. C55-O56-C57 $\left(-\mathrm{CH}_{2} \mathrm{OCH}_{2}-\right)$ was disordered over two positions (0.66:0.34) and restrained using DELU and SIMU. F1-F6 are restrained with DELU and SIMU. Acetone molecule was refined with occupancy of 0.5 and restrained with ISOR and DANG. 
1-Ag1: Single

crystals

of

$\left[\mathrm{Ag}\left(\mathrm{C}_{52} \mathrm{H}_{68} \mathrm{O}_{14}\right)\right] \mathrm{CF}_{3} \mathrm{SO}_{3} \cdot\left(\mathrm{C}_{2} \mathrm{H}_{5} \mathrm{OH}\right)_{0.5} \cdot\left(\mathrm{H}_{2} \mathrm{O}\right)_{1.5} \quad(M=1242.08$ $\mathrm{g} / \mathrm{mol})$ were crystallized from acetone-ethanol-DCM (1:0.2:0.2) solution at $30{ }^{\circ} \mathrm{C}$. Colourless plate crystal $0.1 \times 0.1 \times 0.04 \mathrm{~mm}$, orthorhombic, Pnma (no. 62), $a=21.0806(5) \AA, b=37.7868(8)$ $\AA, c=14.1827(3) \AA, V=11297.5(4) \AA^{3}, T=123.01(10) \mathrm{K}, Z=$ $8, \mu\left(\mathrm{Cu} \mathrm{K}_{\alpha}\right)=3.941, D_{\text {calc }}=1.461 \mathrm{mg} / \mathrm{mm}^{3}, 26573$ reflections measured $(7.86 \leq 2 \theta \leq 153.3), 11658$ unique $\left(R_{\text {int }}=0.0348\right), R_{1}$ $=0.0869(>2 \sigma(\mathrm{I})), \quad w R_{2}=0.2731$ (all data), GoF $=1.041$. $\mathrm{CF}_{3} \mathrm{SO}_{3}^{-}$was disordered over two positions (0.5:0.5) and restrained with DFIX, DELU, SIMU, and constrained with EADP. C51, C52, C55 are disordered over two positions (0.6:0.4), and $\mathrm{C} 36\left(-\mathrm{OCH}_{3}\right)$ over two positions $(0.65: 0.35)$. Hydrogens for $\mathrm{O} 200, \mathrm{O} 205$ and $\mathrm{O} 206$ were located from the electron density and restrained using DFIX 0.84. In addition, AFIX 7 was used for O206. Hydrogens for O203 and O204 were not located but are included in the molecular formula.

1-Ag2: Single crystals of $\left[\mathrm{Ag}_{2}\left(\mathrm{C}_{52} \mathrm{H}_{68} \mathrm{O}_{14}\right)\right]\left(\mathrm{PF}_{6}\right)_{2}\left(\mathrm{C}_{1.5} \mathrm{H}_{4.5} \mathrm{O}_{1.25}\right)$ $(M=1465.29 \mathrm{~g} / \mathrm{mol})$ were crystallized from acetone in 1propanol diffusion with excess of $\mathrm{AgPF}_{6}$. Colourless block crystal $0.3 \times 0.1 \times 0.1 \mathrm{~mm}$, monoclinic, $\mathrm{C} 2 / \mathrm{c}$ (no. 15), $a=$ 19.9517(4) $\AA, b=16.9799(4) \AA, c=17.9735(4) \AA, \beta=$ 105.634(2) ${ }^{\circ}, V=5863.8(2) \AA^{3}, Z=4, T=123.01(10) \mathrm{K}, \mu(\mathrm{Cu}$ $\left.\mathrm{K}_{\alpha}\right)=6.796 \mathrm{~mm}^{-1}, D_{\text {calc }}=1.660 \mathrm{~g} / \mathrm{mm}^{3}, 9992$ reflections measured $(6.94 \leq 2 \theta \leq 148.72), 5684$ unique $\left(R_{\text {int }}=0.0199\right), R_{1}$ $=0.0560(>2 \sigma(\mathrm{I})), w R_{2}=0.1770$ (all data), $\mathrm{GoF}=1.073$. $\mathrm{PF}^{-}$ is located on a special position with F2 and F5 disordered over two positions (0.60:0.40) and restrained with DFIX 1.57, SADI, DELU, and SIMU. Residual electron density arising from solvent could not be modeled and was removed from the final refinement using Mask-option in Olex2. Removed electron density per unit cell, 96 electrons, accounts for approximately two molecules of acetone and three molecules of water $\left(\mathrm{C}_{6} \mathrm{H}_{18} \mathrm{O}_{5}\right)$, which were added to the UNIT.

2-I: Single crystals of $\mathrm{C}_{44} \mathrm{H}_{54} \mathrm{O}_{11} \cdot\left(\mathrm{CDCl}_{3}\right)_{0.5} \cdot \mathrm{H}_{2} \mathrm{O}(M=837.08$ $\mathrm{g} / \mathrm{mol})$ were crystallized from $\mathrm{CDCl}_{3}$. Colourless needle crystal $0.15 \times 0.05 \times 0.05 \mathrm{~mm}$, triclinic, P-1 (no. 2), $a=15.8050(7) \AA$, $b=16.2661(7) \AA, c=18.4549(6) \AA, \alpha=94.688(3)^{\circ}, \beta=$ 95.580(3) ${ }^{\circ}, \gamma=117.328(4)^{\circ}, V=4151.9(3) \AA^{3}, Z=4, Z^{\prime}=2, T$ $=123.00(10) \mathrm{K}, \mu(\mathrm{Cu} \mathrm{K} \alpha)=1.642 \mathrm{~mm}^{-1}, D_{\text {calc }}=1.339 \mathrm{~g} / \mathrm{mm}^{3}$, 25968 reflections measured $(6.18 \leq 2 \theta \leq 149.28), 16157$ unique $\left(R_{\text {int }}=0.0491\right), R_{1}=0.0744(>2 \sigma(\mathrm{I})), w R_{2}=0.2335$ (all data), $\mathrm{GoF}=1.031$. C40-C41-O42-C43-C44-O45-C46-C47 and C90C91-O92-C93-C94-O95-C96-C97 are disordered over two positions (0.8:0.2) and restrained with DFIX and SADI. EADP constrain is used for $\mathrm{C} 40 / \mathrm{C} 40 \mathrm{~B}, \mathrm{C} 90 / \mathrm{C} 90 \mathrm{~B}, \mathrm{C} 47 / \mathrm{C} 47 \mathrm{~B}$, and $\mathrm{C} 44 \mathrm{~B} / \mathrm{O} 45 \mathrm{~B}$. OH hydrogens were located from electron density map and restrained using DFIX 0.82 .

2-II: Single crystals of $\mathrm{C}_{44} \mathrm{H}_{54} \mathrm{O}_{11} \cdot \mathrm{C}_{2} \mathrm{H}_{3} \mathrm{~N}(M=799.93 \mathrm{~g} / \mathrm{mol})$ were crystallized from acetonitrile. Colourless block crystal $0.5 \times 0.5 \times 0.24 \mathrm{~mm}$, monoclinic, P21/c (no. 14), $a=17.5554(3)$ $\AA, b=13.4377(2) \AA, c=19.9408(4) \AA, \beta=114.831(2)^{\circ}, V=$ 4269.23(13) $\AA^{3}, Z=4, T=173.0 \mathrm{~K}, \mu\left(\mathrm{Mo} \mathrm{K}_{\alpha}\right)=0.088 \mathrm{~mm}^{-1}$, $D_{\text {calc }}=1.245 \mathrm{~g} / \mathrm{mm}^{3}, 14501$ reflections measured $(6.46 \leq 2 \theta \leq$ $52), 8041$ unique $\left(R_{\text {int }}=0.0159\right), R_{1}=0.0434(>2 \sigma(\mathrm{I})), w R_{2}=$ 0.1104 (all data), $\mathrm{GoF}=1.023 . \mathrm{CH}_{3} \mathrm{CN}$ is disordered over two positions (0.5:0.5) and restrained using DFIX, DELU and SIMU. EADP constrain is used for C101, N100, C102, and $\mathrm{C} 105$. OH hydrogens were located from electron density map and restrained using DFIX 0.82 .

\section{Acknowledgements}

Academy of Finland (project 2100001911) and Emil Aaltonen foundation are acknowledged for funding.

\section{Notes and references}

${ }^{a}$ University of Jyvaskyla, Department of Chemistry, Nanoscience Center, P.O. Box 35, FI-40014 University of Jyvaskyla, Finland

Electronic Supplementary Information (ESI) available: synthetic procedures, hydrogen bond tables, and selected bond lengths and torsion angles. See DOI: 10.1039/b000000x/

${ }^{1}$ Y. Aoyama, Y. Tanaka, and S. Sugahara, J. Am. Chem. Soc., 1989, 111, 5397-5404; P. Timmerman, W. Verboom, and D. N. Reinhoudt, Tetrahedron, 1996, 52, 2663-2704; W. Sliwa, C. Kozlowski, Calixarenes and Resorcinarenes Synthesis, Properties and Applications, Wiley-VCH, Germany, 2009.

${ }^{2}$ L. C. Palmer, A. Shivanyuk, M. Yamanaka, and J. Rebek Jr, Chem. Commun., 2005, 5, 857-8; L. Avram and Y. Cohen, Org. Lett., 2008, 10, 1505-8; S. Kunsági-Máté, Z. Csók, K. Iwata, E. Szász, and L. Kollár, J. Phys. Chem. B, 2011, 115, 3339-3343.

${ }^{3}$ B.-Q. Ma, Y. Zhang, and P. Coppens, Cryst. Growth Des., 2001, 1, 271275; D. J. Eisler and R. J. Puddephatt, Inorg. Chem., 2003, 42, 6352 6365 .

${ }^{4}$ K. N. Rose, L. J. Barbour, G. W. Orr, and J. L. Atwood, Chem. Commun., 1998, 407-408; A. A. Momose and E. Bosch, Cryst. Growth Des., 2010, 10, 4043-4049.

${ }^{5}$ H. Mansikkamäki, M. Nissinen, and K. Rissanen, Chem. Commun., 2002, 1902-1903.

${ }^{6}$ H. Mansikkamäki, M. Nissinen, and K. Rissanen, CrystEngComm, 2005, 7, 519-526.

${ }^{7}$ L. R. MacGillivray and J. L. Atwood, Nature, 1997, 389, 469-472.

${ }^{8}$ T. Gerkensmeier, W. Iwanek, C. Agena, R. Fröhlich, S. Kotila, C. Näther, and J. Mattay, Eur. J. Org. Chem., 1999, 2257-2262.

${ }^{9}$ H. Mansikkamäki, M. Nissinen, and K. Rissanen, Angew. Chem. Int. Ed., 2004, 43, 1243-1246.

${ }^{10}$ Shivanyuk, E. F. Paulus, K. Rissanen, E. Kolehmainen, and V. Böhmer, Chem. Eur. J., 2001, 7, 1944-51.

${ }^{11}$ J. R. Moran, S. Karbach, and D. J. Cram, J. Am. Chem. Soc., 1982, 104, 5826-5828; D. J. Cram, Science, 1983, 219, 1177-1183.

${ }^{12}$ See for review: T.-R. Tero and M. Nissinen, Tetrahedron, 2014, 70, 1111-1123.

${ }^{13}$ I. Higler, H. Boerrigter, W. Verboom, H. Kooijman, A. L. Spek, and D. N. Reinhoudt, Eur. J. Org. Chem., 1998, 1597-1607.

${ }^{14}$ T. Friscic and L. R.MacGillivray, J. Organomet. Chem., 2003, 666, 4348.

${ }^{15}$ Y. Zhang, C. D. Kim, and P. Coppens, Chem. Commun., 2000, 22992300; B.-Q. Ma and P. Coppens, Chem. Commun., 2003, 504-5.

${ }^{16}$ L. R. MacGillivray, J. L. Reid, and J. A. Ripmeester, Chem. Commun., 2001, 2, 1034-1035. 
${ }^{17}$ B.-Q. Ma, Y. Zhang, and P. Coppens, Cryst. Growth Des., 2001, 1, 271-275; B.-Q. Ma and P. Coppens, Chem. Commun., 2003, 412413.

${ }^{18}$ L. R. Macgillivray, K. T. Holman, and J. L. Atwood, J. Supramol. Chem., 2001, 1, 125-130.

${ }^{19}$ B.-Q. Ma, Y. Zhang, and P. Coppens, Cryst. Growth Des., 2002, 2, 713.

${ }^{20}$ P. O. Brown, G. D. Enright, and J. A. Ripmeester, J. Supramol. Chem., 2002, 2, 497-500; Q. Ma and P. Coppens, Cryst. Growth Des., 2004, 4, 211-213; A. Åhman, M. Luostarinen, K. Rissanen and M. Nissinen, New J. Chem. 2007, 31, 169-177; J. M. Matheny, E. Bosch, and C. L. Barnes, Cryst. Growth Des., 2007, 7, 984-988; C. L. Barnes and E. Bosch, J. Chem. Crystallogr., 2007, 37, 783-786; M. Lepakshaiah and T. N. Guru Row, J. Mol. Struct., 2009, 918, 1013.

${ }^{21}$ B.-Q. Ma, Y. Zhang, and P. Coppens, J. Org. Chem., 2003, 68, 946772; B.-Q. Ma and P. Coppens, Cryst. Growth Des., 2004, 4, 13771385; R. S. Patil, A. V. Mossine, H. Kumari, C. L. Barnes, and J. L. Atwood, Cryst. Growth Des., 2014, 14, 5212-5218.

22 B.-Q. Ma and P. Coppens, Chem. Commun., 2002, 424-425; A. Nakamura, T. Sato and R. Kuroda, CrystEngComm, 2003, 5, 318325.

${ }^{23}$ B.-Q. Ma, Y. Zhang, and P. Coppens, CrystEngComm, 2001, 3, 78-80; T. Gerkensmeier, C. Agena, W. Iwanek, R. Fröhlich, S. Kotila, C. Näther, and J. Mattay, Z. Naturforsch., B Chem. Sci., 2001, 56, 10631073; P. O. Brown, G. D. Enright, and J. A. Ripmeester, CrystEngComm, 2006, 8, 381-383.

${ }^{24}$ M. He, R. J. Johnson, J. O. Escobedo, P. A. Beck, K. K. Kim, N. N. St. Luce, C. J. Davis, P. T. Lewis, F. R. Fronczek, B. J. Melancon, A. A. Mrse, W. D. Treleaven, and R. M. Strongin, J. Am. Chem. Soc., 2002, 124, 5000-9.

${ }^{25}$ L. R. MacGillivray and J. L. Atwood, J. Am. Chem. Soc., 1997, 119, 6931-6932; R. Kuzmicz, V. Kowalska, S. Domagała, M. Stachowicz, K. Wozniak, and W. Koldziejski, J. Phys. Chem. B, 2010, 114, 10311-10320.

${ }^{26}$ L.R. MacGillivray, H.A. Spinney, J.L. Reid, J.A. Ripmeester, Chem. Commun., 2000, 517-518.

${ }^{27}$ M. J. McIldowie, M. Mocerino, B. W. Skelton, and A. H. White, Org. Lett., 2000, 2, 3869-3871.

${ }^{28}$ T.-R. Tero, A. Suhonen, K. Salorinne, H. Campos-Barbosa, and M. Nissinen, Org. Lett., 2013, 15, 1096-1099.

${ }^{29}$ K. Salorinne and M. Nissinen, Org. Lett., 2006, 8, 5473-5476.

${ }^{30}$ K. Helttunen, K. Salorinne, T. Barboza, H. Campos Barbosa, A. Suhonen, and M. Nissinen, New J. Chem., 2012, 36, 789-795.

${ }^{31}$ K. Salorinne, T. Tero, K. Riikonen, and M. Nissinen, Org. Biomol. Chem., 2009, 7, 4211-4217.

${ }^{32}$ K. Salorinne and M. Nissinen, Tetrahedron, 2008, 64, 1798-1807.

${ }^{33}$ K. Salorinne, O. Lopez-Acevedo, E. Nauha, H. Häkkinen, and M. Nissinen, CrystEngComm, 2012, 14, 347-350.

${ }^{34}$ K. Helttunen, N. Moridi, P. Shahgaldian, and M. Nissinen, Org. Biomol. Chem., 2012, 10, 2019-2025.

${ }^{35}$ K. Salorinne and M. Nissinen, CrystEngComm, 2009, 11, 1572-1578.
${ }^{36}$ K. Salorinne, E. Nauha, and M. Nissinen, Chem. Asian J., 2012, 7, 809-817.

${ }^{37}$ Z. Otwinowski and W. Minor, Methods Enzymol., 1997, 276, 307-326.

${ }^{38}$ CrysAlisPro, Agilent Technologies, Version 1.171.36.21 (release 1408-2012 CrysAlis171 .NET).

${ }^{39}$ G.M. Sheldrick, Acta Crystallogr., Sect. A: Found. Crystallogr., 2008, 64, 112-122.

${ }^{40}$ O. V. Dolomanov, L. J. Bourhis, R. J. Gildea, J. A. K. Howard and H. Puschmann, J. Appl. Cryst., 2009, 42, 339-341. 